\title{
RESEARCH "BORN IN THE CLASSROOM": STUdentS' ERRORS AS A SOURCE OF KNOWLEDGE?
}

\author{
RAFFAELLA MAigUASHCA
}

\section{(INTRODUCED AND EDITED By ANNE URBANCIC)}

\section{Honouring the Work of Prof. Raffaella Maiguashca (d. 1999)}

In 1998 the publication of a report by The Boyer Commission on Educating Undergraduates in the Research University heralded an incontrovertible change on post-secondary teaching. Entitled Reinventing Undergraduate Education: A Blueprint for America's Research Universities, it openly confronted the tension in the academe between research and teaching. Its recommendations have had profound and ineluctable ramifications on all universities today, not only in North America, but also throughout the world. We would be hard pressed now to find an institution of higher learning where there is no tangible support for teaching. These are offices that function with the important assistance of presidents, provosts, and deans.

The fundamental first recommendation of the Commission was to "make research-based learning the standard" (15). Essentially, this recommendation acknowledges that teaching and research go hand in hand. Traditionally, research was done outside the classroom, but eventually passed into the knowledge taught in the classroom. However, the innovative, even radical, proposal of the Commission was that research was also born in the classroom and that teaching could, and does, lead to valid, valuable research that follows the criteria demanded for all investigative projects, whether in the sciences or in the humanities. The first recommendation clearly advises that

Undergraduate education in research universities requires renewed emphasis on a point strongly made by John Dewey almost a century ago: learning is based on discovery guided by mentoring rather than on the transmission of information. Inherent in inquiry-based learning is an element of reciprocity: faculty can learn from students as students are learning from faculty (15).

The Report also emphasizes that 
Because of the unique character of a research university, the process of discovery is essentially a public one; the results of research are, through both teaching and publication, offered publicly for critique, correction, and extension. Undergraduates need to become an active part of the audience for research. In a setting in which inquiry is prized, every course in an undergraduate curriculum should provide an opportunity for a student to succeed through discovery-based methods. (17)

Professor Raffaella Maiguashca was already very ill at the time the Boyer Commission published its findings. Had she read it, she would undoubtedly have agreed wholeheartedly with many of its proposals. Indeed, she had already worked with similar attitude and approach for many years. Maiguashca was a gifted and generous teacher, a "natural" in the classroom. Students loved her; graduate students sought her out to be their mentor. Her enthusiasm and love for teaching were contagious. She worked assiduously and diligently; years previously she had understood somehow that she was an 'intuitive pedagogue'; she just knew how to make the lesson, the course, the curriculum, the textbooks work. We know now that she was also at the vanguard of post-secondary teaching, particularly in teaching of IFL (Italian as a Foreign Language). The acronyms and buzz words that inform current approaches in the teaching of IFL were practices that she demonstrated without giving them a name. Her classroom was her research lab, much as the Boyer Commission had advocated. She worked carefully and methodically to arrive at new findings valuable to all IFL instructors. This is clear in the study that follows. She had planned a much longer article; this is only the first third of her research "born in the classroom." Unfortunately her illness cut short her valuable contributions, so the article remains unfinished. On the occasion of the tenth anniversary of her passing (she died in January 1999), we offer here her last written contribution to Italian studies. In it she proposes a new way of considering a problematic aspect of Italian language teaching, one that still today requires more exploration. Her work, "born in the classroom," demonstrates her pioneering spirit. It was ahead of its time and remains valid today. The article is published here for the first time with the kind permission of her husband, Prof. Juan Maiguashca. Let this essay, as is, remain as a tribute to a truly inspiring teacher and researcher.

\author{
ANNE URBANCIC \\ ViCTORIA COLLEGE \\ UNIVERSITY OF TORONTO
}




\section{RESEARCH "BORN IN THE CLASSROOM”: STUdENTS' ERRORS AS A SOURCE OF KNOWLEDGE?}

The realization that knowledge is not always something that is imparted to learners by an omniscient teacher, but rather something that can be searched or discovered within the classroom, while interrelating with one's students, dawned upon me at the very beginning of my career as second-language teacher. Specifically, I am a teacher of Italian working with Englishspeaking learners in the Canadian context. First, I am an educated native speaker of Italian and, as a linguist, I have spent years studying and researching this language. This does not mean, of course, that I have a clear and explicit knowledge of every single rule that governs its use. Second, I discovered early in my career that I could not always count on pedagogical textbooks or even on reference grammars and dictionaries to fill the gaps in my knowledge, or to answer questions and clear up dubious points. None of those books contain a complete and detailed description of every morphological, syntactic, semantic, and stylistic aspect of the language. While they certainly offer the language teacher reliable and useful maps to consult, nevertheless, the vast and complex territory of language will always present untraveled roads and uncharted regions.

The awareness of these gaps in my knowledge of Italian, followed by the need to fill them through research, has occurred and continues to occur at different moments of my teaching: in preparing lessons, in presenting a complex point to the class, in answering students' questions or in marking their work. However, nowhere does it occur more frequently and more strikingly than when I find myself confronted by some of my students' errors. It is true that most of the time the correction poses no problem. In fact, the students themselves, during La caccia all'errore (Error Hunt), a class exercise devised expressly for that purpose, are able to identify and correct their own mistakes and even discuss them in terms of the relevant rules of Italian. There are times, however, when they do not seem to recognise or understand where or why they erred; they even question the corrections and explanations. Typically, in these cases, they use English as a point of reference, that is, they try to analyse the Italian sentence or expression in terms of its English translation equivalent, which is of course quite different. At this point it becomes clear that the mistake is the result of what is called "interference" or "transfer" from their native tongue.

Transfer of grammatical rules or lexical meanings from one language to another can be of help only in areas where the two languages are alike. Inevitably, transfer leads to error when the languages are different. Error 
hunting, in these cases, can be very rewarding not only for students, but also for the teacher, for it brings to light an interesting structural or lexical contrast between the two languages. Such a contrast may not have been studied yet and begs for further investigation by the linguist: it is a contrast that would never be noticed by someone doing research from a monolingual perspective, that is, when studying Italian or English alone. The second-language classroom situation, which by definition implies a bilingual perspective, provides a fertile soil for research in "contrastive analysis," which is the systematic comparison between the students' native language (L1) and the target language (L2-in this case English and Italian-in order to highlight similarities and differences between the two.

From the point of view of research, this systematic comparison with English is often an eye opener. It helps us see the Italian data from a different perspective and this sometimes leads me, quite unexpectedly, to the discovery of idiosyncratic, distinctive features of Italian that not only were unknown to me personally, as a teacher, but are not generally well known in the field of Italian linguistics. For example, rules may not have been spelled out in Italian reference grammars, or semantic properties of words may not be recorded or exemplified in standard dictionaries. In this way what is initially error hunting in the classroom becomes a catalyst that directs the teacher towards research in "contrastive linguistics." It provides me with the initial empirical data as well as a hypothesis to be investigated. Many of my own research projects and published articles have been, and will continue to be, the outcome of classroom discussions.

Two important points must be made about this research "born in the classroom." The first has to do with the fact that its findings sometimes go beyond the discovery of the workings of Italian and involve broader issues, theoretical or pedagogical in nature. For example, in the next section, which focuses on grammatical errors, we shall see how the discovery of a certain structural contrast between English and Italian puts into question the concept of "the subject of the sentence" in general, forcing both teacher and students to discuss the problem and to think about it critically. In a similar way, the following section, dedicated to vocabulary errors, will show how the identification of certain lexical contrasts between English and Italian has implications greater than the simple comparison between the meaning of a certain word in one language and its supposed equivalent in the other. In fact, it calls into question the whole concept of "the meaning of words" and brings to light the problems of using translation as a method in second-language teaching.

The second important point about this research "born in the class- 
room" is that it allows a teacher to get students involved in it as engaged and active participants. Their involvement starts right in the classroom, when it becomes clear that the teacher is not imposing pre-fabricated notions on them but rather discovering knowledge with them. That is the moment when their interest and curiosity are first kindled, as they became aware that a linguistic phenomenon may be unclear and should be investigated further, a sort of problem to be solved. Later on, their involvement can be sustained through individual or group assignments and projects. In the next sections the reader will be able to appreciate the role of students' participation in my research.

In sum, what I hope to show is that teaching and research are not always, as often thought, two separate and independent activities in which academics engage - research being essentially the quest for knowledge and teaching the dissemination of it. There are times and situations when these two activities overlap and merge, in the sense that teaching can actually "trigger" research by posing interesting problems and pointing to possible solutions. When this happens, the quality of learning improves dramatically, at least for some students. Even in beginners' language courses, which are seen by some as nothing more than the acquisition of "communicative skills," learners can be encouraged to go beyond the mere ability to perform in a second or foreign language. For example, they can learn to tackle and re-think some fundamental concepts about language that are often used, but totally taken for granted. More importantly, they can be given an opportunity to participate in the exciting process of research and discovery of knowledge.

Below I shall offer an example of a research project which was actually "born in the classroom." The starting point was provided by the students' errors and the particular by the class exercise devoted to error correction, La caccia all'errore. This is followed by the "contrastive analysis" which highlights the difference between Italian and English and shows how the errors are a case of "interference" or "transfer" from the native language (L1) to the target language (L2). To conclude, I offer a brief summary of the research I carried out based on those initial data and of the results obtained.

Before we pass on to the examples, however, it may be useful to give a short description of the exercise named La caccia allerrore. The data for this special class activity, namely, the list of errors to be discussed, are usually prepared at home while marking the students' work. I select from their writings a number of sentences, perhaps four or five, that exhibit the same "type" of error: for instance, lack of subject-verb agreement, wrong choice 
of past tense, incorrect auxiliary verb, failure to use the subjunctive mood, inappropriate use of word, and so on. Once in class, the sentences are written on the blackboard and the class is asked to (a) identify the common error, (b) discuss its cause in terms of the relevant role, and finally (c) rewrite the sentences with appropriate corrections.

This exercise proves to be useful for a number of reasons. First, it exploits the principle of analogy in the sense that if the error in question is unclear in one sentence, by the time the whole set has been discussed, the majority of students have understood it properly. Second, the focus is on the forms, both incorrect and correct, and never on the student who committed the error. Third, the whole activity is class-centred rather than teacher-centred, namely, apart from the initial set up, it is managed almost entirely by the students themselves, who actually learn from each other. Last, but certainly not least, there are times when the discussion about the origin or cause of the error leads to "contrastive analysis," and it is often in this context that the ideas for future research emerge.

\section{Grammatical Errors: Subject-Verb Agreement.}

The first illustration of research "born in the classroom" is in the area of grammar. More specifically, I shall give an account of how the analysis and classroom discussion of certain errors made by my students regarding subject-verb agreement constituted for me the initial step of a research project that eventually led me to discover a particular type of syntactic structure which I call "equation copular sentence" and to formulate the rules that govern its use in Italian-rules that, as far as I know, had never been studied before.

I was teaching a beginners' course in Italian for Anglophone students at York University, Canada. As is customary in beginners' classes of Italian, one of the first rules of syntax taught and drilled is the subject-verb agreement, which requires that the verb agree with the subject of the sentence in terms of "person" (first, second, or third),"number" (singular or plural), and, in some cases, "gender" (masculine or feminine). The concept of subject-verb agreement is not difficult for the students to absorb and apply. After all, except for "gender," the same rule exists in English, the students' native tongue. As for the concept of "subject," again, the definitions used for pedagogical purposes—such as "agent" (the person or thing that does the action expressed by the verb) or "topic" (the person or thing which is being talked about) — are the same for both Italian and English. I never expected to have problem in this area of grammar. 
Sometime in the middle of the first term, however, long after I had taught the rule of subject-verb agreement had been taught, I was surprised to find in my students' homework a number of errors concerning this point. I decided to devote a few minutes of class to review it. Following the usual routine of La caccia all'errore, I wrote on the blackboard a set of four sentences taken from the students' own writings. To make the exercise as effective as possible, I chose what I thought were simple, basic sentences. In all of them the main verb was essere (to be), and they happened to have a very similar, almost identical, structure. The sentences are reproduced below, the asterisk being the conventional symbol for grammatical unacceptability. The English translation is provided in the column at the right.

* (1) Il mio passatempo preferito È i libri.

My favourite pastime is books.

* (2) La nazione più potente È gli Stati Uniti.

The most powerful nation is the U.S.

* (3) Il problema È i miei genitori.

The problem is my parents.

* (4) La mia unica speranza $\grave{E} t u$ !

My only hope is you!

In retrospect, I have to admit my initial unawareness of the complex nature of these sentences and of the problems they pose for Englishspeaking learners. This discovery came later. At first, the lesson concentrated on the fact that all the sentences on the blackboard exhibited the same type of error: the form of the verb $\grave{E}$ (is), which is third person singular, was wrong in all cases because it did not agree with the subject. More specifically, and for the sake of the readers who are not speakers of Italian, in the first three sentences (1-3) the verb should be "plural" in number because the subject is a plural noun: e.g. i libri (books), gli Stati Uniti (the United States) and i miei genitori (my parents). In sentence (4), on the other hand, the verb should be in the "second person" because the subject is the secondperson pronoun $t u$ (you). Below is the list of the correct sentences, where both subject and verb are underlined and where the subject of the sentence, although it follows the verb, governs the form of the verb:

(1) I1 mio passatempo preferito sono i libri.

(2) La nazione più potente sono gli Stati Uniti.

(3) I1 problema sono i miei genitori.

(4) La mia unica speranza sei tu ! 
Proceeding in the usual way, I asked the students to identify the error common to the sentences, discuss its cause, and provide the correct form. Much to my surprise, however, no appropriate answer was forthcoming. Whereupon, I reminded the class about the rule of subject-verb agreement in Italian and began to apply it to sentence (1). "What is the subject of this sentence?" I asked. Obviously i libri (books), I said, which is a plural noun. Accordingly, the verb should also be plural: "II mio passatempo preferito sono i libri." I hoped of course that, by analogy, the students would apply the same reasoning to the other sentences.

This did not happen, however. If anything, they appeared even more confused by my explanation. The problem seemed to lie in identifying the subject of each sentence. The students asked repeatedly why the subject of the Italian sentence (1) was $i$ libri and not il mio passatempo preferito. In English, the students pointed out, it is the other way around: the singular noun "My favourite pastime" functions as subject and governs the singular verb ("is"), while the plural noun "books" functions as noun-predicate. The same analysis was applied to the English sentence (2): the singular noun "The most powerful nation" is the subject and the verb ("is") agrees with it, while the plural noun "the United States" is a noun-predicate. And the same can be said of sentences (3) and (4). In short, in English the subject was the noun, or noun phrase, that opened the sentence.

Their observations about English were correct. By then, it became evident that their errors were the result of "interference" or "transfer" from English. I told the class to leave English aside for the time being and focus once again on the correct Italian sentence (1): "I1 mio passatempo preferito sono i libri." The subject, I insisted, namely the concrete, specific topic I am talking about, is really $i$ libri (books). The predicate, namely, what I am saying about books, is that they are my favourite pastime. In an effort to prove my point, I repeated the sentence very emphatically, this time starting with i libri: "I libri sono il mio passatempo preferito!!!"

This last move provoked an immediate reaction from the students. Of course, they said, in English too if one starts the sentence with "books" the verb becomes plural: "Books are my favourite pastime!!!!" However, they continued, if one begins with "My favourite pastime ...," then the verb is singular. They pointed out that the same rule applies to all the English sentences including the last (4). If one begins with the noun "my only hope," the verb is in the third person: "My only hope is you." If the order is reversed, however, and one begins with the second-person pronoun "you," the verb changes to second person: "You are my only hope." In short, the class agreed, in English the verb changes according to the position of the nouns: 
i.e. whichever noun (or noun phrase) comes first and opens the sentence is the subject, and the verb agrees with it.

Once again, the analysis of the English data provided by the students was absolutely correct. I proceeded to summarize and illustrate the subjectverb agreement rule in English with the following table, where the boldface represents the government of the subject over the verb:

(1) Books $\underline{\text { ARE my favourite pastime }}$

My favourite pastime $\underline{I S}$ books.

(4) My only hope $\underline{I S}$ you.

\section{You $\underline{A R E}$ my only hope.}

Immediately after, however, I returned to the situation in Italian. I reminded the class that languages differ greatly in their grammatical and lexical structures. The particular type of sentence illustrated a case in point. In Italian, unlike in English, the verb does not change if the order of the nouns is reversed. In other words, the verb agrees with one and only one of the two nouns, which functions as subject of the sentence irrespective of its position. The corresponding table for Italian graphically shows the contrast with English:

(1) I libri SONO il mio passatempo preferito.

$I 1$ mio passatempo preferito $\underline{\text { SONO }}$ i libri.

(4) Tu SEI la mia unica speranza.

La mia unica speranza SEI tu.

At this point, as was to be expected, the students responded with a barrage of questions. How could they have known, they asked, which one of the two nouns functions as subject in Italian? Why is it that in the first three Italian sentences (1-3) the verb always agrees with the plural noun and not with the singular: was this a rule that they had not studied yet? And regarding sentence (4) - where you have a noun phrase (third person) and the pronoun $t u$ (second person) — why does the verb agree with the pronoun and not with the noun? Is this always the case? Is it a rule? 
These were difficult questions for which I did not have a ready answer. Clearly, we were not dealing with simple, basic Italian sentences as I had thought at the beginning, but rather with a complex structure of Italian syntax that not only showed a marked difference with English, but was not treated in current Italian textbooks. In fact, as far as I could remember, I had never seen it discussed in theoretical treatises of Italian syntax or in publications on contrastive analysis. Thanks to my classroom experience, I found myself with a substantial research project in my hands, a project for which I already had a framework. By this I mean that the key questions were already clear in my mind and, perhaps, also some tentative or preliminary hypotheses, which had emerged during that long and laborious error hunting exercise with my students.

Four questions came to mind. The first concerned the nature of the object under study. In sentences such as those above, how should their syntactic structure be characterized? Initially all that was known was that in each one, the main verb was essere (to be), that they had two nouns (or noun phrases or pronouns), and that the subject-verb agreement rule was different for English and Italian.

The second question had to do precisely with this difference and therefore required detailed "contrastive analysis" of the two languages. For the moment, based on the limited data observed, we had established that in English, in case of discrepancy between the two nouns either in number or in person, the verb always agrees with the noun that occurs first. Word order, then, seemed to be the determining factor. In Italian, on the other hand, the data analyzed in class indicated, at least on the surface, that the form of the verb does not depend on the position of the nouns, since it sometimes agrees with the first noun and sometimes with the second.

The third question concerned exclusively the Italian syntax. If "word order" is irrelevant, how can one predict which of the two nouns will govern the verb in Italian? In other words, what are the rules that govern the subject-verb agreement in this type of sentence? The data considered in the classroom were insufficient to formulate these rules. What was needed was a systematic examination of the three cases of discrepancy that can occur between the two nouns: number, person, and gender.

Finally, above and beyond these three language-specific questions, a fourth issue, theoretical in nature, caused much concern. I refer to the general concept of subject of the sentence. In retrospect, I realized that my way of dealing with student errors had not been appropriate. I had assumed that the concept of subject was unproblematic and that my students ought to be able to identify the subject of the Italian sentences. After my 
friendly confrontation with them, however, I realized that was a tall order indeed. What criteria did I expect them to apply in order to recognise the subject? What notion or definition? Certainly not that of agent, given that the verb essere (to be) is not a verb of action: there are no actions performed nor agents performing them in any of the sentences under consideration. Nor is the notion of topic applicable because each of the sentences exhibits two topics, namely the two nouns linked by the verb essere, both equally suitable candidates to play the role of subject, as the English sentences clearly show. So my students had no alternative but to draw from their knowledge of their native tongue. Hence the transfer from English, and consequently, the error. This shows that current pedagogical notions of "subject" are not sufficient, or at least they do not cover the case of the sentences under study. Could a more suitable definition of subject be formulated?

So much for the questions. Let us now turn to the results of my research. Not all my questions were fully answered. This seldom happens: taking a few steps towards knowledge is a more likely outcome.

My point of departure was to identify and define the type of sentence under consideration and to characterize its syntactic structure. We have seen that the main verb is essere (to be), so we know that we are dealing with a type sentence called a copular sentence. Various kinds of copular sentences exist, as can be seen from the following examples:

(1) Roma È splendida.

(2) Roma È una città italiana.

(3) Roma È la capitale d'Italia.
Rome is splendid.

Rome is an Italian city.

Rome is the capital of Italy.

Sentence (3) has different characteristics from the first two. To begin with, from the syntactic point of view, it is "reversible," while the other two are not. We can reverse the word order in Roma È la capitale d'Italia and obtain an equivalent and perfectly normal basic sentence, La capitale d'Italia È Roma. Likewise, "Rome is the capital of Italy" can be reversed into "The capital of Italy is Rome." With the other two sentences this transformation is impossible without loss of meaning. Secondly, from the point of view of semantic logic, in sentence (3) the copula " $\bar{E}$ " establishes a relation of "identity" between the two nouns (Roma and la capitale d'Italia) whereby one serves to identify the other. In the other two sentences, instead, the relation established is one of class membership, namely, Rome belongs to the class of Italian cities or to the class of splendid things. Lastly, from the point of view of semantics, sentence (3) represents an "equation" between the two nouns, which are both specific. The other two, instead, 
are simply attributive, the attribute being either an adjective (splendida) or an indefinite noun (una città italiana).

The following table summarizes and illustrates the structure of this particular type of sentence, which I have called "equation copular sentence":

$\begin{array}{lll}\text { Noun Phrase 1 } & \text { Verb: copula } & \text { Noun Phrase 2 } \\ \text { Roma } & \grave{E} & \text { la capitale d'Italia } \\ \text { la capitale d'Italia. } & \grave{E} & \text { Roma. }\end{array}$

What we have here is two definite noun phrases $(N P)$ linked by a copula: $N P 1+$ copula $+N P 2$. Note that the numbering of the two NPs indicates simply their linear order of occurrence in the sentence: we call NP1 that noun which precedes the copula and NP2 the one that follows it. In other words, the numbering has nothing to do with the syntactic function of the $N P$; it has no bearing on whether it functions as subject of the sentence or as noun predicate. The distinguishing syntactic property of this type of sentence is reversibility: the order of the two NPs can be reversed as in a mathematical equation $X=Y$ or $Y=X$. Hence the term "equation copular sentences".

Having established the specific structure of the sentence, the next step in my research was to look into the rules that govern subject-verb agreement in these "equation copular sentences," both in English and more particularly in Italian. The reader will have noticed that in the example given above, "Roma È la capitale d'Italia," the problem of agreement does not exist because both NPs ( "Roma" and "la capitale d'Italia") require the verb to be in the third person singular; in this case, reversing the order of the $N P$ s does not alter the form of the verb. The problem arises when there is a difference between the two NPs, either in number (one $N P$ is singular and the other is plural) or in person (one of the two NPs is a noun and the other a first-or-second-person pronoun) or in gender (one $N P$ is masculine and the other feminine).

This aspect of the investigation began with a broadening of the "contrastive" perspective through the addition of French sentences to the collection of linguistic data. The analysis of the English data confirmed the tentative hypothesis formed in the classroom - that is, the copula always agrees in person and number with NP1. In other words, NP1 invariably functions as subject of the sentence. The study of French data, surprisingly, showed that exactly the same rule applies as in English, as can be seen from the following examples: Les livres sont mon seul plaisir and Mon seul plaisir c'est les livres; or Je suis le roi and Le roi c'est moi. Thus word order 
was found to be the determining factor in subject-verb agreement in both these languages.

In Italian, on the other hand, word order is irrelevant and the copula agrees with one and only one of the two $N P_{s}$, irrespective of its position in the sentence. The question was: which one? After an exhaustive examination of the Italian data, and considering the three categories of agreement in Italian, three rules emerged:

(1) NUMBER. When one NP is singular and the other is plural, the copula is always plural: e.g. "I polmoni sono l'organo della respirazione.," "L'organo della respirazione sono i polmoni." [Lungs are the organ of respiration. / The organ of respiration is the lungs] This confirmed the tentative, preliminary hypothesis we had formulated in the classroom.

(2) PERSON. When one $N P$ is a noun and the other is a first-person or second-person pronoun, the copula always agrees with the pronoun: e.g. "Io sono il padrone!," "I1 padrone sono io!" [I am the boss]

(3) GENDER. When one $N P$ is masculine and the other is feminine, the copular verb agrees with the most "concrete" of the two NPs: "Laura $\grave{E}$ stata il mio più grande amore.," "I1 mio più grande amore $\grave{E}$ stata Laura. "[Laura was my greatest love. / My greatest love was Laura.]

Finally, with regard to the issue of providing a definition of subject that would fit the case of the "equation copular sentences" (other than that of agent or topic), a conclusive answer could not be found. I was only able to open the discussion and suggest ways of continuing the research.

I conclude here my first example of "research born in the classroom." As can be seen, my project yielded some tangible results as far as Italian is concerned. I was able to identify a particular syntactic structure that had not been studied before and to formulate the rules that govern it. In a more general way this is still an open project, to be further developed in the future. What I hope to have shown here, however, is that the first seed was planted in the classroom while I discussed their errors with my students. Had it not been for those errors and for that discussion, I may have never become aware of that unexplored area of Italian grammar.

York UnIVERSITY, CANADA 


\section{Cited WORKS}

The Boyer Commission on Educating Undergraduates in the Research University. Reinventing Undergraduate Education: A Blueprint for America's Research Universities. Stony Brook, NY?: State University of New York at Stony Brook for the Carnegie Foundation for the Advancement of Teaching, 1998. 